\title{
Imaging of Peptides in the Rat Brain Using MALDI-FTICR Mass Spectrometry
}

\author{
Ioana M. Taban, A. F. Maarten Altelaar, Yuri E. M. van der Burgt, \\ Liam A. McDonnell, Ron M. A. Heeren \\ FOM Institute for Atomic and Molecular Physics, Amsterdam, The Netherlands
}

Jens Fuchser and Gökhan Baykut

Bruker BioSciences/Bruker Daltonik GmbH, Bremen, Germany

Analytical methods are pursued to measure the identity and location of biomolecules down to the subcellular $(\mu \mathrm{m})$ level. Available mass spectrometric imaging methods either compromise localization accuracy or identification accuracy in their analysis of surface biomolecules. In this study, imaging FTICR-MS is applied for the spatially resolved mass analysis of rat brain tissue with the aim to optimize protein identification by the high mass accuracy and online MS/MS capabilities of the technique. Mass accuracies up to $6 \mathrm{ppm}$ were obtained in the direct MALDI-analysis of the tissue together with a spatial resolution of $200 \mu \mathrm{m}$. The spatial distributions of biomolecules differing in mass by less than $0.1 \mathrm{Da}$ could be resolved, and are shown to differ significantly. Online MS/MS analysis of selected ions was demonstrated. A comparison of the FTICR-MS imaging results with stigmatic TOF imaging on the same sample is presented. To reduce the extended measuring times involved, it is recommended to restrict the FTICR-MS analyses to areas of interest as can be preselected by other, faster imaging methods. (J Am Soc Mass Spectrom 2007, 18, 145-151) (c) 2007 American Society for Mass Spectrometry

I n several diseases such as Alzheimer's, cancer, obesity, etc., malfunctioning proteins or protein fragments (i.e., peptides) plays a crucial role. Changes in protein function can be caused by a number of events such as altered localization [1-3], posttranslational modifications [4-7], or expression levels [3, 8]. Studying these events is a challenging area because of the dynamics of the cellular proteome and the sensitivity of the molecules of interest to fluctuations in their natural surroundings. Recently, imaging mass spectrometry (IMS) has been recognized as a proteomic tool for in situ spatial analysis of (diseased) tissue [9, 10]. Matrixassisted laser desorption/ionization (MALDI) MS has been shown to be able to determine the localization of native biomolecular components like proteins and peptides in tissue [11-15]. Often, the data includes several unknown species with a spatial distribution that indicates it is associated with a disease or biochemicallyaltered region of the tissue. A strategy that combines high mass resolution mass spectrometry with imaging has the potential to directly identify these unknown compounds. In addition to the high mass resolution, online tandem mass spectrometry further can aid in compound identification.

Published online October 19, 2006

Address reprint requests to Dr. R. M. A. Heeren, Macromolecular Ion Physics and Biomolecular Mass Spectrometry, FOM Institute for Atomic and Molecular Physics, Kruislaan 407, 1098 SJ Amsterdam, The Netherlands. E-mail: heeren@amolf.nl
In most laboratories, time-of-flight (TOF) MS is used for peptide imaging directly from biological tissues. Both MALDI $[16,17]$ and secondary ion mass spectrometry (SIMS) [18-20] approaches can provide good mass resolution images $\left(\sim 10^{4}\right)$. MALDI can be used for the analysis of high mass species (up to $100 \mathrm{kDa}$ ) at low spatial resolution (pixel size $>25 \mu \mathrm{m}$ ) [11]. Very high spatial resolution is obtained using SIMS (pixel size $<1$ $\mu \mathrm{m})$ [19], however its sensitivity rapidly decreases with increasing mass, making the technique less suited for protein analysis. Surface modification techniques such as metal assisted SIMS or matrix enhanced SIMS can be used to extend the useable mass range to small peptides and proteins [14, 21-30].

Two mass spectrometric imaging approaches currently exist: microprobe and microscope mode imaging. In microprobe IMS experiments, the ionization beam is rastered over the sample surface, acquiring a mass spectrum at each $\mathrm{x}, \mathrm{y}$-coordinate. Mass resolved images or spectra from regions of interest are then extracted from the dataset. The spatial resolution obtained in MALDI microprobe imaging is typically in the 100 to $200 \mu \mathrm{m}$ range, limited by the size of the laser spot used $[31,32]$. The development of micrometer resolution has been reported [33], however decreasing spot size has been found to lead to decreasing sensitivity for high mass species. An alternative approach for high spatial resolution IMS is the mass microscope. Here the spatial resolution is about $4 \mu \mathrm{m}$ [34] and independent of the 
spot size of the ionizing beam, but solely dependent on the ion optics of the instrument and the kinetic energy distribution of the MALDI-generated ions. The desorbed molecules retain their original spatial distribution during the TOF analysis and are projected onto a position sensitive detector. The mass microscope can record the spatial information from within the spot of the MALDI laser beam with $4 \mu \mathrm{m}$ spatial resolution (600 nm pixel size). By using laser spots of $200 \mu \mathrm{m}$ diameter, a high-resolution image is obtained with each laser shot. Because the mass microscope is also a TOF mass analyzer, an image is obtained for each analyte. In a microprobe experiment, this spot would constitute a single pixel for each analyte [34].

By using MALDI-FTICR (Fourier transform ion cyclotron resonance) MS it is possible to combine high resolving power, high mass accuracy, and the possibility of performing multistage MS/MS experiments [3538] allows peptide identification directly from tissue [39]. ${ }^{\circ}$ The ${ }^{\circ}$ FTICR $^{\circ}$ imaging $^{\circ}$ strateg ${ }^{\circ}$ extends $^{\circ}$ the $e^{\circ}$ identification possibilities in direct tissue analysis and is a valuable tool in MS imaging instrumentation.

For the first time, MALDI-FTICR-MS was used for imaging of rat brain tissue sections. In the study described in this paper, the left half of a rat brain tissue section was imaged with FTICR-MS and the right half with the mass microscope MALDI-TOF. The resulting images were compared to demonstrate the strength of the high mass resolution, accurate mass measurements made with the FTICR-MS, and its added value to imaging experiments. In addition, on-line FTICR-MS fragmentation techniques were used to identify a neuropeptide found during the tissue analysis.

\section{Experimental}

\section{Tissue Sections}

Experimental procedures were in accordance with the European directives (86/609/EEC) and approved by the Commission on Laboratory Animal Experiments of the University Medical Center Utrecht. Male Wistar rats (Crl:WU) weighing $350 \mathrm{~g}$ were obtained from Charles River. Rats were decapitated without prior anesthesia, and brains were dissected and frozen in liquid isopentane, cooled to $-50{ }^{\circ} \mathrm{C}$ on dry ice, and then stored at $-80^{\circ} \mathrm{C}$ until sectioning. The $10-\mu \mathrm{m}$-thick rat brain tissue sections were cut at interaural $7.2 /$ bregma -1.8 $\mathrm{mm}^{\circ}[40],{ }^{\circ}$ using $^{\circ} \mathrm{a}^{\circ}$ cryomicrotome. ${ }^{\circ}$ Sections ${ }^{\circ}$ were $^{\circ}$ thawmounted on indium-tin-oxide-coated glass slides and were stored at $-80^{\circ} \mathrm{C}$ until use. Before mass spectrometry, tissue sections were slowly brought to room temperature in a desiccator.

The rat brain tissue sections were washed twice in $70 \%$ cold ethanol (Biosolve, Valkenswaard, The Netherlands) for $1 \mathrm{~min}$. After washing, the tissue sections were allowed to dry for $30 \mathrm{~min}$ after which the matrix was $^{\circ}$ applied $^{\circ}[41]^{\circ}$ using $^{\circ}$ a $^{\circ}$ TLC $^{\circ}$ sprayer $^{\circ}\left[42,{ }^{\circ} 43\right]^{\circ}(30$
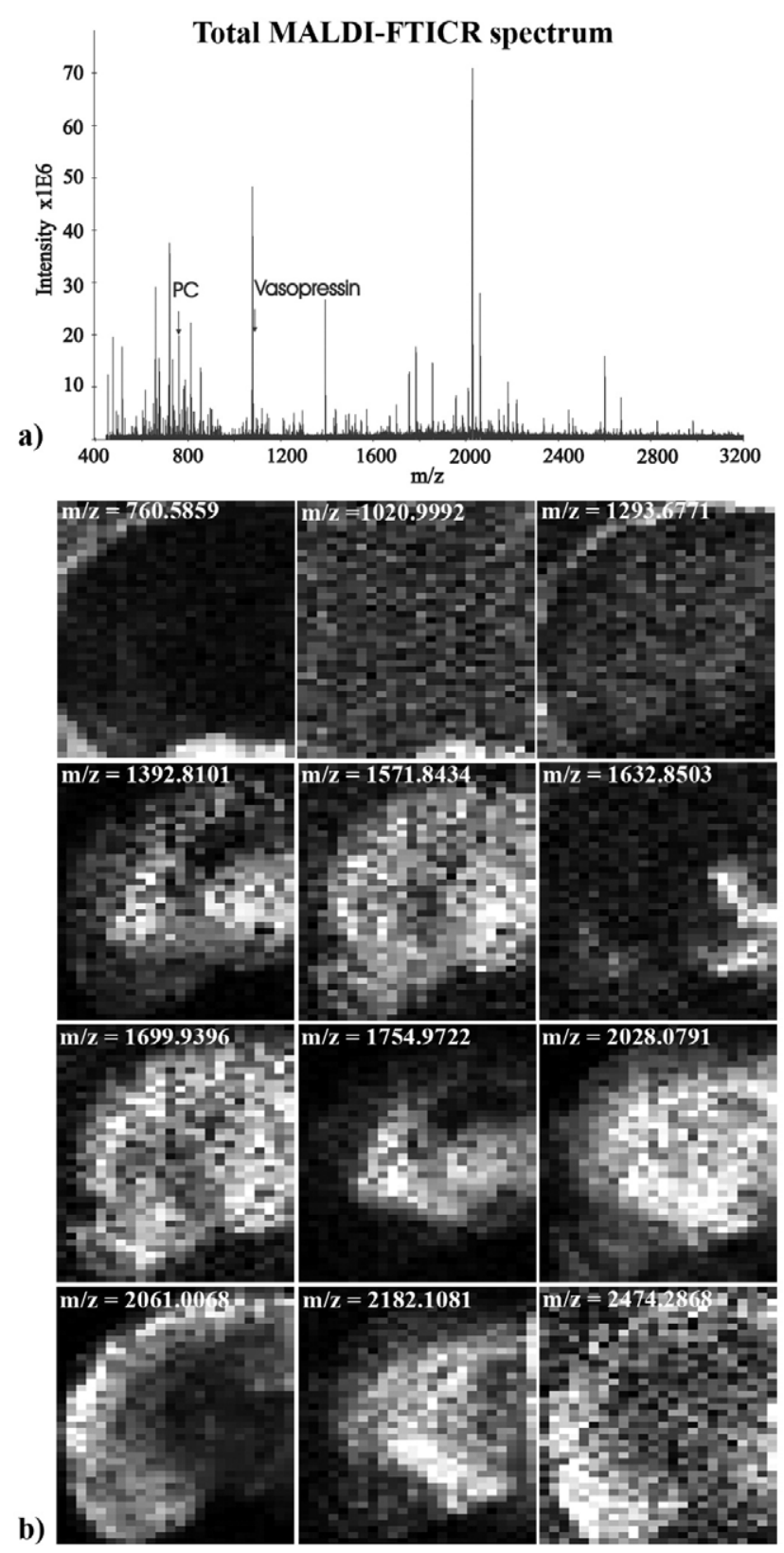

Figure 1. (a) Total MALDI-FTICR spectrum of the left side of the rat brain tissue; (b) the rat brain with white representing the highest relative intensity for each $\mathrm{m} / \mathrm{z}$ value.

$\mathrm{mg} / \mathrm{mL}$ of 2,5-dihydroxybenzoic acid in 50:50 ethanol/ water and $0.1 \%$ trifluoroacetic acid). The sample was then covered with a $3 \mathrm{~nm}$ layer of gold using a plasma sputter coater (Quorum Technologies, Newhaven, United Kingdom).

\section{Mass Spectrometry}

FTICR-MS. FTICR-MS experiments were performed on an APEX III FTICR mass spectrometer (Bruker Daltonics, ${ }^{\circ}$ Billerica, $\left.{ }^{\circ} \mathrm{MA}\right)^{\circ}[44]^{\circ}$ equipped $^{\circ}$ with a $7 \mathrm{~T}$ superconducting magnet and a combined electrospray / MALDI source ("CombiSource"). 


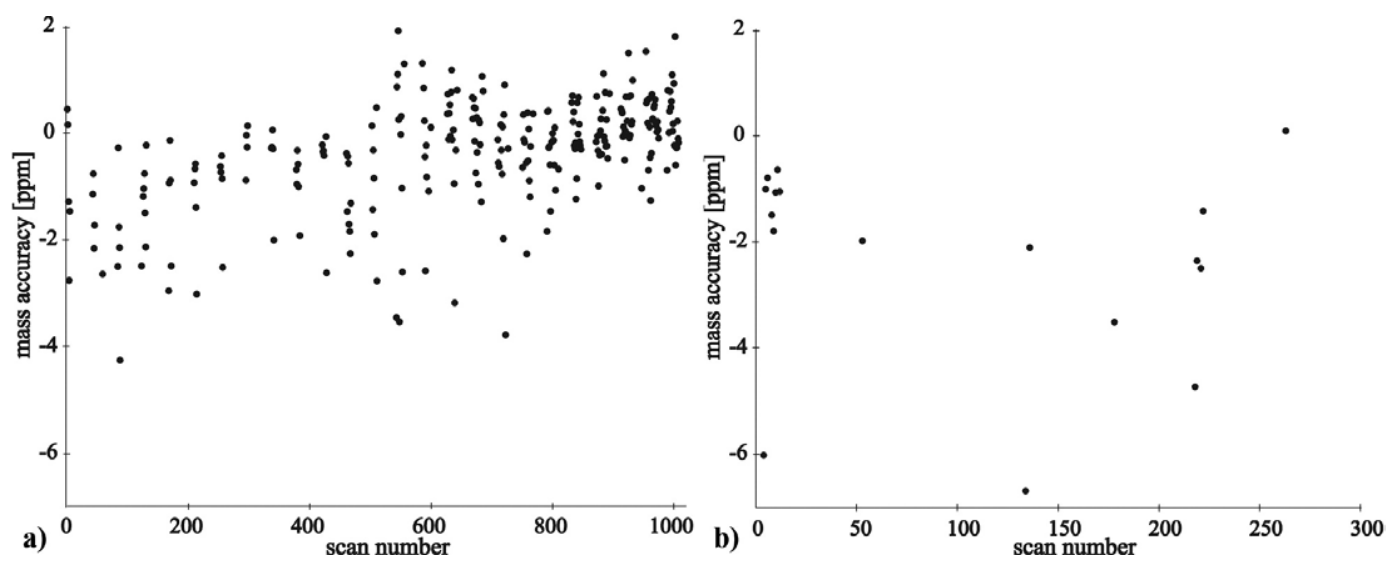

Figure 2. Mass accuracy of PC and vasopressin for the FTICR image of the left side of the rat brain tissue section. Neutral masses were used for calculations.

During FTICR-MS experiments, collision gas was pulsed into the medium pressure chamber housing a hexapole ion trap before firing the nitrogen laser $(\lambda=$ $337 \mathrm{~nm}$, laser repetition rate $=20 \mathrm{~Hz}$, laser spot diameter $200 \mu \mathrm{m}$ on the target). The ions, cooled by collisions, were captured and accumulated in the hexapole (10 laser shots per spectrum) located in the front of the target and then further guided to the cell for mass analysis or tandem MS experiments. Isolation and fragmentation were performed in different sections of the ion guides before ions enter the ICR cell, for some of the MS/MS experiments presented in the paper.

Compass software (Bruker Daltonics, Billerica, MA) was used to control the instrument. Atlas Control software (Bruker) was additionally used to control the sample stage. This enabled an accurate setting of the step size for the imaging experiments. Each image of half a brain section spans an area $\sim 7.2 \times 8.4 \mathrm{~mm}$ and comprises $24 \times 42$ pixels of $300 \times 200 \mu \mathrm{m}$ dimensions.

TOF. MALDI-TOF experiments were performed on a heavily modified TRIFT II (Physical Electronics, Eden Prairie, MN) instrument incorporating an ion optical microscope $[34,45,46]$. ${ }^{\text {The }}$ TRIFT ${ }^{\circ}{ }^{\circ}$ mass ${ }^{\circ}$ spectrometer is equipped with a $\mathrm{Nd}$ :YAG laser $(\lambda=355 \mathrm{~nm}$, repetition rate $=10 \mathrm{~Hz}$, oval spot $=150 \times 200 \mu \mathrm{m})$. The data recording for the microprobe and microscope analysis is done simultaneously in this TRIFT set-up. The sample stage was continuously moved at $100 \mu \mathrm{m} / \mathrm{s}$ while recording $150 \times 200 \mu \mathrm{m}$ total-ion-count (TIC) images and full spectra with each laser shot. To cover half of the rat brain tissue section, 65 line scans (the distance between two line scans is $120 \mu \mathrm{m}$ ), each containing 850 individual single-shot images were acquired. The size of each pixel for the TOF microprobe images overlaying the TIC stigmatic image was chosen to be $10 \times 120 \mu \mathrm{m}$.

Data processing. The visualization software, DataCubeViewer (FOM-AMOLF, Amsterdam, The Netherlands), allows the generation of selected ion images from the FTICR-MS dataset. The minimum mass window that can be selected is $0.1 \mathrm{Da}$. This value was used for all images shown in this paper. The intensities of the selected mass range are binned together. In the resulting image, white represents the highest relative intensity. The spectra of individual linescans can be examined ${ }^{\circ}$ with the in-house ${ }^{\circ} \mathrm{AWE}{ }^{\circ}$ and ${ }^{\circ} \mathrm{AWE} \mathrm{D}^{\circ}$ software [47].

For the TOF images, the individual TIC single-shot images were combined to form a linescan and, subsequently, all linescans were assembled to construct the total image, using in-house software (Spatial Image Composer $)^{\circ}$ [48]. ${ }^{\circ}$ The $^{\circ}$ position-correlated ${ }^{\circ}$ TOF $^{\circ}$ mass spectra were used to generate microprobe images of specific peaks using the same software.

\section{Results and Discussion}

Imaging

In this study, a comparison between microprobe MALDI-FTICR-MS imaging and microscope TOF-MS imaging was made. The symmetry of a rat brain tissue section makes it an ideal sample for such a comparison. To ensure a fair comparison, the two techniques were applied to opposing halves of a single tissue section and multiple replicates made for confirmation. Two different brain tissue sections were imaged and different areas of interest on other brain tissues sections and pituitary gland sections were studied. An optical inspection of the sample during the various stages of the experiment ensured that the transfers between mass spectrometers did not lead to the loss of matrix material. All the analyses were performed within $48 \mathrm{~h}$ from their preparation.

The use of DHB matrix provides more intense signals in MALDI FTICR-MS of neuropeptides and less fragmentation of the ions compared with other matrices. $^{\circ}$ Figure $^{\circ} 1^{\circ}$ shows $^{\circ}$ the $^{\circ}$ total $^{\circ}$ mass $^{\circ}$ spectrum $^{\circ}$ of ${ }^{\circ}$ the MALDI-FTICR-MS analysis of the left side of the rat brain tissue section together with some representative images of the selected ions. It is clear from the figure that this approach can provide a wealth of biochemical 
a)
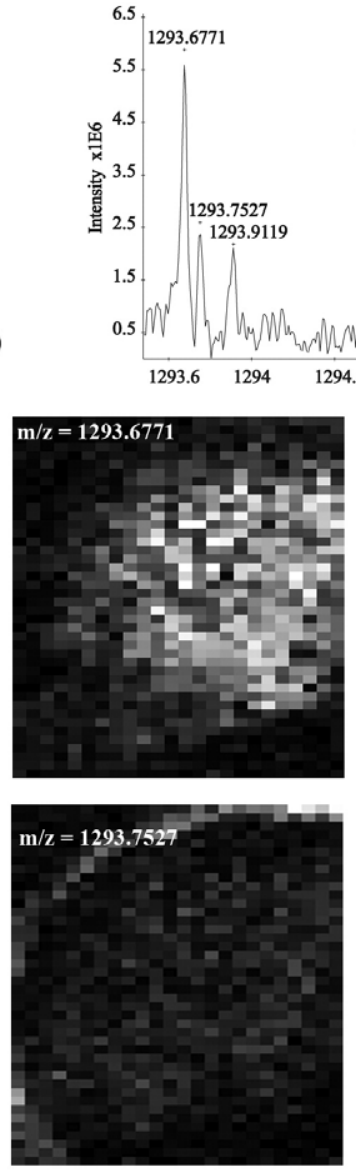

b)

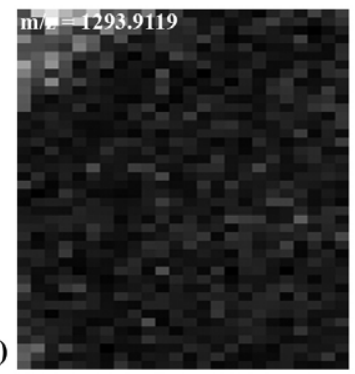

1294.6813

1294.9136

1295.9056 1294.7688

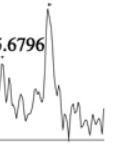

$\begin{array}{lllll}1294.8 & 1295.2 & 1295.6 & 1296 \\ \mathrm{~m} / \mathrm{z} & & & \end{array}$

d)

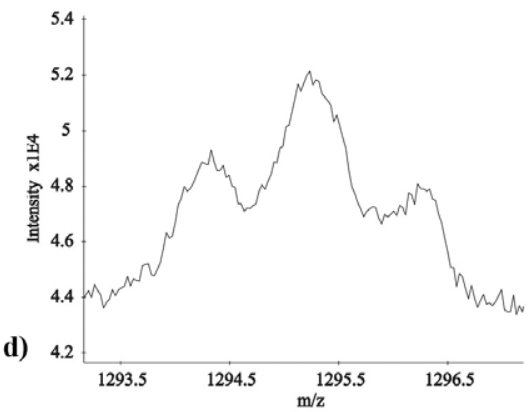

$11.5+$
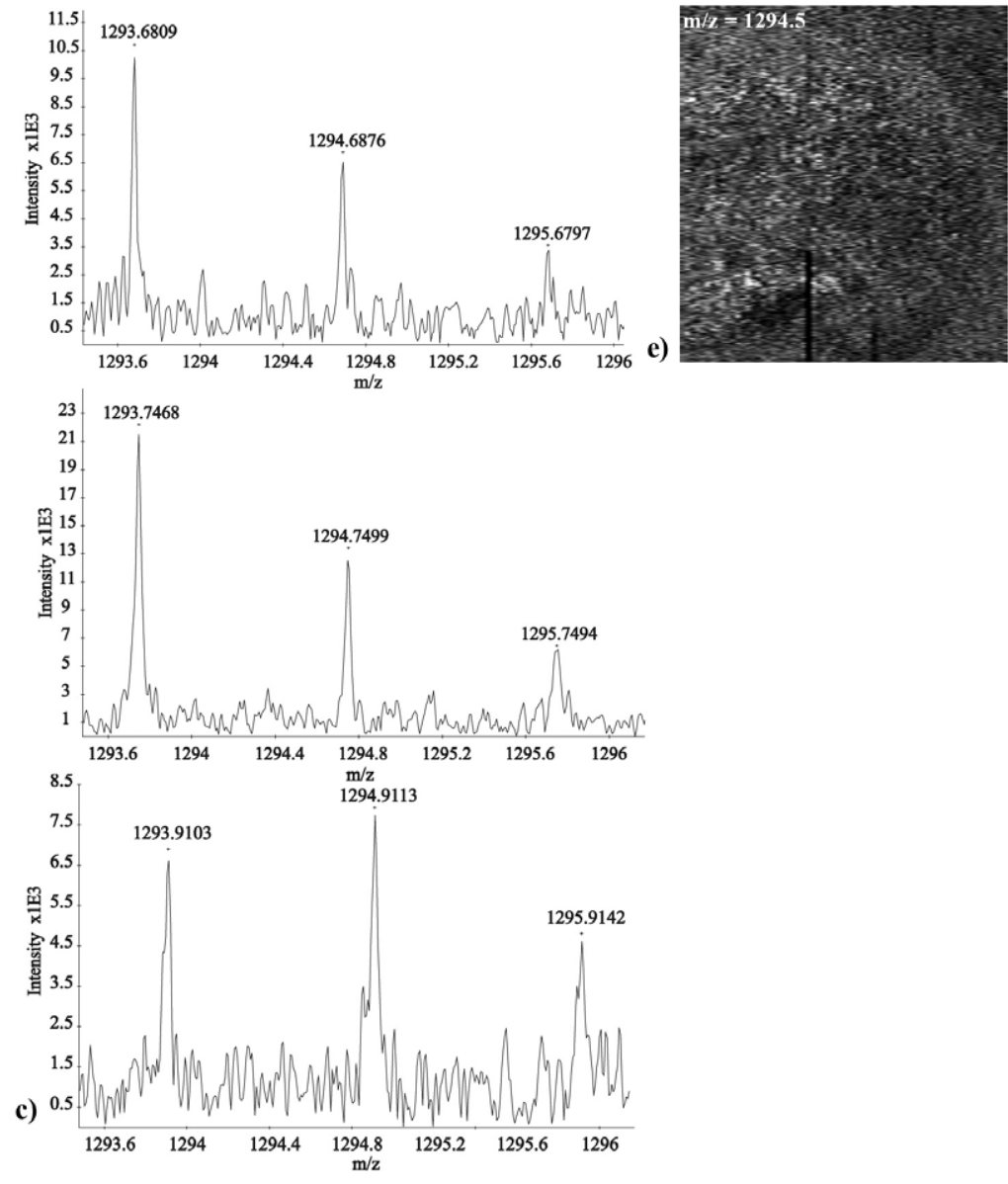

Figure 3. (a) Selected region of the FTICR summed spectrum of half of the rat brain tissue section; (b) FTICR selected ion images of the first isotope of three different compounds; (c) region of interest analysis reveals the spectrum of each individual component; (d) selected region of the summed spectrum of half of the rat brain tissue section; (e) the TOF selected ion image of $m / z=1294$. Due to a technical problem, a part of a line scan of TOF experiments is not present in the selected ion images.

information and that various biomolecules have significantly different spatial distributions. The selected ion images show the distribution of the monoisotopic peak of the compounds.

Peptide identification is greatly facilitated using accurate mass FTICR-MS, even allowing positive identification if the proteome is small and the mass accuracy

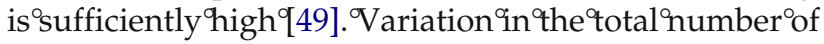
ions entering the ICR cell will affect the mass accuracy, thus calibration of the spectra with an internal calibrant is required for such peptide identification. Alternatively, known lipids located in the brain can be used as internal calibrants, as these lipids are present in all spectra. Here, we have restricted ourselves to external calibration.

The observed variation of the mass accuracy of phosphatidylcholine $(\mathrm{m} / \mathrm{z}=760.5856)$ and vasopressin are $^{\circ}$ shown $^{\circ}$ in $^{\circ}$ Figure $^{\circ} 2 a^{\circ}$ and $^{\circ} b^{\circ}$ for ${ }^{\circ}$ this ${ }^{\circ}$ externally ${ }^{\circ}$ calibrated imaging dataset. This figure was generated by examining the mass accuracy of the selected peaks above a set noise threshold for all linescans contained in the ${ }^{\circ}$ image. The ${ }^{\circ}$ number ${ }^{\circ}$ of $^{\circ}$ points ${ }^{\circ}{ }^{\circ}{ }^{\circ}$ Figure $2 b^{\circ}$ is ${ }^{\circ}$ limited because vasopressin is present in a limited number of locations in the tissue. The mass accuracy of these 
compounds after external calibration is found to be $\sim 6$ ppm or lower. The number of laser shots was chosen so that the number of ions trapped in the ICR cell was not excessive, thus ensuring high mass accuracy. Internal calibration would improve the accuracy even further.

Figure $^{\circ} 3^{\circ}$ demonstrates $^{\circ}$ the ${ }^{\circ}$ utility $^{\circ}$ of $^{\circ}$ high $^{\circ}$ mass $^{\circ}$ resolution ${ }^{\circ}$ FTICR $^{\circ}$ mass $^{\circ}$ spectrometry. $^{\circ}$ Figure $^{\circ} 3 a^{\circ}$ shows $^{\circ}$ a selected region of the total mass spectrum. The three different compounds and their isotopes, $\mathrm{m} / \mathrm{z}=$ $1293.6771,1293,7527,1293.9119$, present in this very narrow mass range, show the high-resolution and quality of the FTICR-MS data. Moreover, these three species exhibit a different spatial distribution in the rat brain as shown ${ }^{\circ}$ in ${ }^{\circ}$ the ${ }^{\circ}$ images ${ }^{\circ}$ in ${ }^{\circ}$ Figure $^{\circ} 3 b^{\circ} .^{\circ}$ Figure $^{\circ} 3 c^{\circ}$ shows ${ }^{\circ}$ the corresponding region-of-interest spectra, providing spectral information on the three individual components (Note the small differences in mass reflect the different number of ions generated in different positions, the cause of the 6 ppm mass errors). The lower mass resolution of the TOF imaging, which requires a constant extraction field, cannot resolve these components and so this distinction cannot be made, and the image combines the spatial distribution of each component $^{\circ}\left(\right.$ Figure $^{\circ} 3 \mathrm{~d}^{\circ}$ and $^{\circ}$ e). ${ }^{\circ}$ This $^{\circ}$ example $^{\circ}$ clearly $^{\circ}$ demon- $^{-}$ strates the advantage of high mass resolution FTICR in imaging mass spectrometry over medium mass resolution TOF.

Figure $4 \mathrm{a}^{\circ}$ shows ${ }^{\circ}{ }^{\circ}$ comparison ${ }^{\circ}$ (MALDI-FTICR 9 left side of the brain) and MALDI TOF imaging experiments $^{\circ}$ (right ${ }^{\circ}$ side $^{\circ}$ of ${ }^{\circ}$ the ${ }^{\circ}$ brain), ${ }^{\circ}$ Figure $^{\circ} 4 b^{\circ}$ an $^{\circ}$ optical image ${ }^{\circ}$ taken ${ }^{\circ}$ after $^{\circ}$ the ${ }^{\circ}$ imaging $^{\circ}$ experiments, ${ }^{\circ}$ and ${ }^{\circ}$ Figure $4 \mathrm{c}^{\circ} \mathrm{a}^{\circ}$ schematic $^{\circ}$ of ${ }^{\circ}$ the $^{\circ}$ rat $^{\circ}$ brain $^{\circ}$ tissue $^{\circ}$ section $^{\circ}$ at ${ }^{\circ}$ bregma $-1.8 \mathrm{~mm}$. The distribution of the neuropeptide vaso$\operatorname{pressin}^{\circ}$ (green) ${ }^{\circ}$ is ${ }^{\circ}$ included ${ }^{\circ}{ }^{\circ}{ }^{\circ} F_{i g u r e} 4 a .{ }^{\circ} \mathrm{As}^{\circ} \mathrm{Can}^{\circ} \mathrm{be}^{\circ}$ seen, the vasopressin is localized around the third ventricle between the supraoptic nuclei, in agreement with previous ${ }^{\circ}$ studies $\left[50^{\circ}-52\right]$. The ${ }^{\circ}$ FICR-MS ${ }^{\circ}$ mages ${ }^{\circ}$ are'microprobe images, whereas the TOF images are microprobe images for selected ions overlaying the TIC stigmatic image (grey scale). This overlay allows the localization of the peptides within the brain to be readily identified. All images are not smoothed. As can be seen, the vasopressin distributions acquired with the two techniques is very similar albeit not identical. This demonstrates that compounds of interest localized with the ion optical microscope time-of-flight can be imaged with high mass resolution on the FTICR-MS on the same tissue section.

A further advantage of using FTICR-MS for direct tissue imaging and profiling is the availability of multistage tandem mass spectrometry for peptide sequencing and identification. Different dissociation techniques, such as sustained off-resonance irradiation collision-induced dissociation (SORI-CID), infrared multi-photon dissociation (IRMPD), and CID in an external linear ion trap are available with the FTICR set-up. ${ }^{\circ}$ Figure ${ }^{\circ} 5 \mathrm{a}^{\circ}$ shows $^{\circ}$ the ${ }^{\circ} \mathrm{MS} / \mathrm{MS}^{\circ}$ spectrum $^{\circ}$ of ${ }^{\circ}$ vasopressin obtained by CID in an hexapole located in front of the ICR cell. The accurate parent ion mass and the

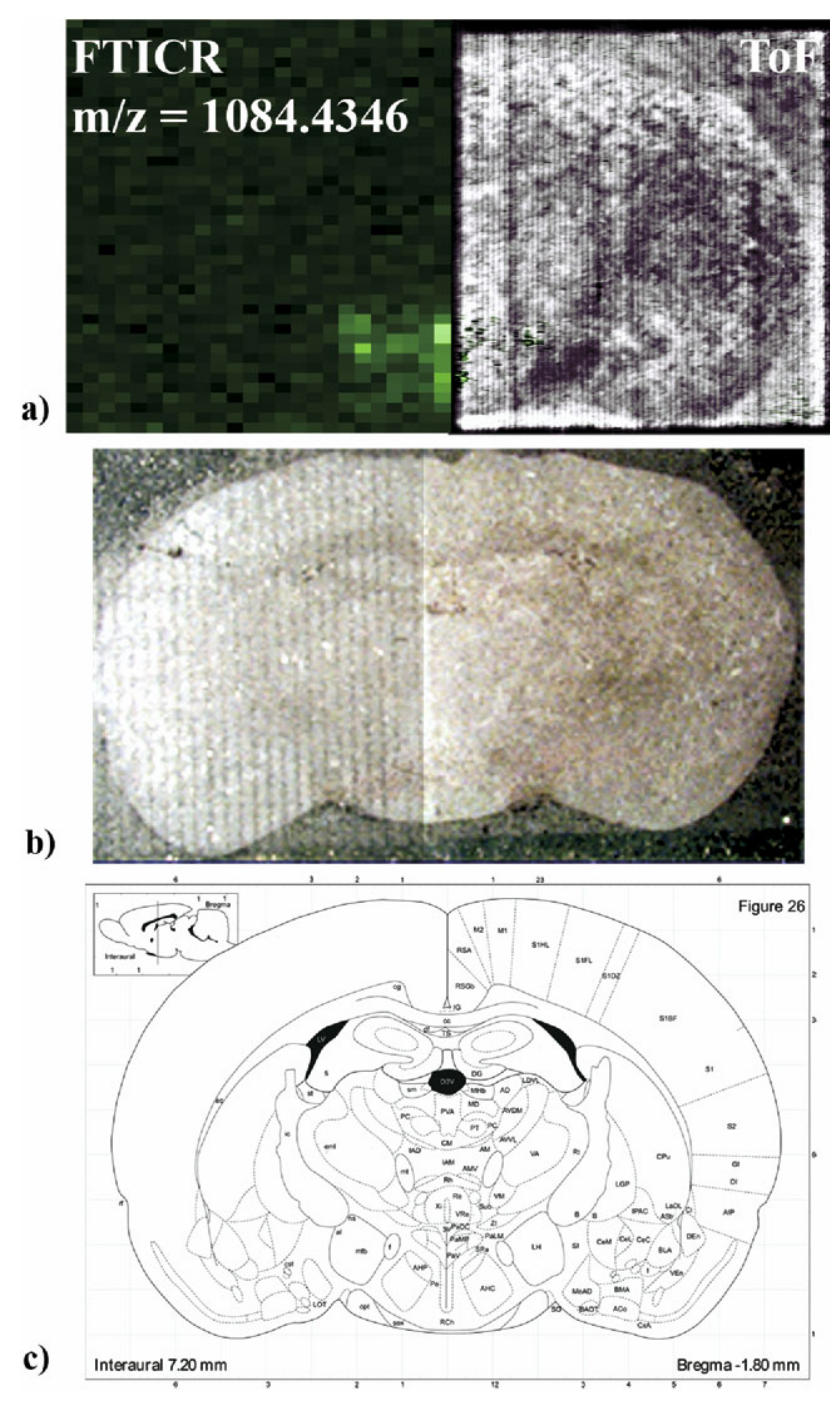

Figure 4. FTICR (left) and TOF (right) images of (a) the distribution of Vasopressin $m / z=1084.44$ on the brain section in green. For clarity in the right hand side TOF image, the vasopressin distribution is overlain on the total ion image in black and white. (b) Optical image with FTICR-MS laser tracks on the left clearly visible. (c) Schematic representation of the anatomy of the rat brain tissue section with the specification where the tissue was taken from the brain.

accurate masses of the $b 6$ and $b 8$ fragment ions were sufficient for positive identification of this neuropeptide. Only a few fragments are CID generated (even for high collisions energies) due to the presence of a disulfide ${ }^{\circ}$ bond. ${ }^{\circ}$ Figure ${ }^{\circ} 5 b^{\circ}$ shows ${ }^{\circ}$ the ${ }^{\circ}$ IRMPD ${ }^{\circ}$ spectrum of $m / z=2028$, which is very abundant in the rat brain (see ${ }^{\circ}$ Figure $\left.^{\circ} 1 \mathrm{a}\right) .{ }^{\circ}$ Despite ${ }^{\circ}$ many ${ }^{\circ}$ fragments ${ }^{\circ}$ obtained ${ }^{\circ}$ with both IRMPD and SORI-CID (not shown) the identity of this ion remains elusive.

\section{Conclusions}

For the first time, FTICR-MS imaging of endogenous neuropeptides and lipids was performed directly on rat brain tissue. The high mass resolution of the FTICR-MS 


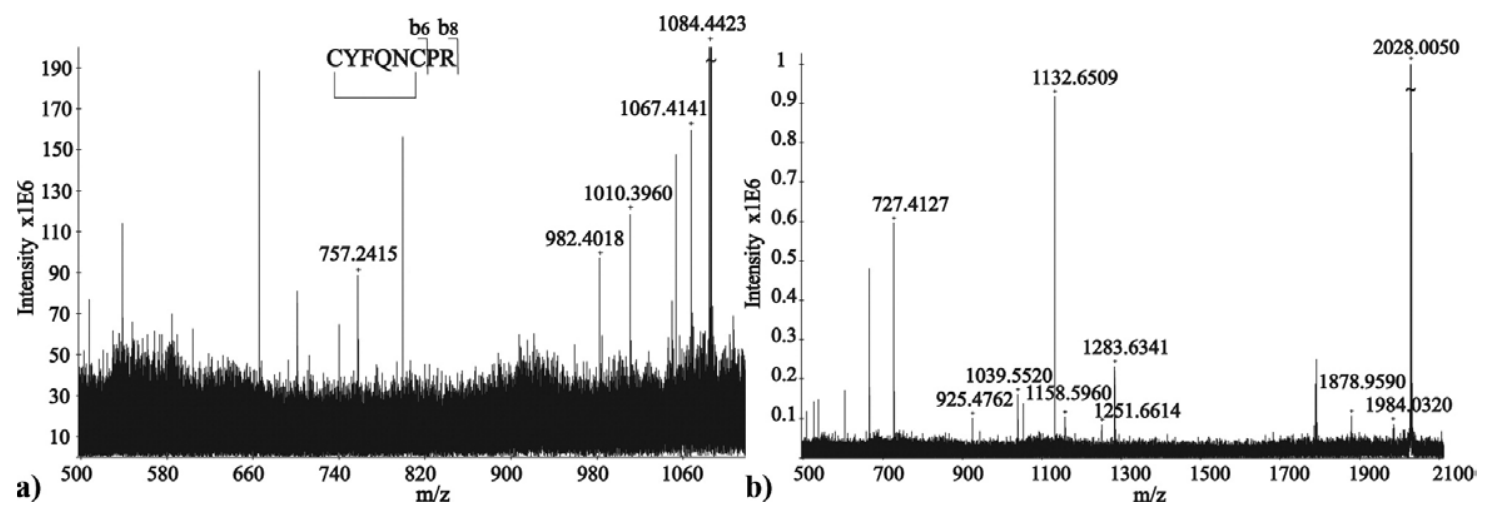

Figure 5. (a) CID of Vasopressin, (b) IRMPD, for $m / z=2028$.

can reveal the localization of different compounds that cannot be distinguished with lower mass resolution TOF based imaging techniques. To perform a highresolution FTICR-MS imaging experiment of an entire rat brain tissue section is very time-consuming (almost one day for this brain tissue section). However, spatial profiling of small-areas of interest combined with MS/MS analysis makes the approach a valuable tool. The real benefit of the technique is profiling small tissue areas to elucidate the peptide sequences of unknowns, thus complementing high spatial resolution stigmatic TOF imaging.

\section{Acknowledgments}

The authors acknowledge with gratitude Roger A. H. Adan for providing us with rat brain tissue samples. Ivo Klinkert, Marco Konijnenburg, and Marco Seynen are acknowledged for continuous software support. This work is part of FOM research program 49 mass spectrometric imaging and structural analysis of biomacromolecules of the Stichting voor Fundamenteel Onderzoek der Materie (FOM), which is financially supported by the Nederlandse organisatie voor Wetenschappelijk Onderzoek (NWO).

\section{References}

1. Calero, M.; Chen, C. Z.; Zhu, W.; Winand, N.; Havas, K. A.; Gilbert, P. M.; Burd, C. G.; Collins, R. N. Dual Prenylation is Required for Rab Protein Localization and Function. Mol. Biol. Cell 2003, 14, 1852-1867.

2. Zaccai, M.; Lipshitz, H. D. Role of Adducin-Like (hu-li tai shao) mRNA and Protein Localization in Regulating Cytoskeletal Structure and Function During Drosophila oogenesis and Early Embryogenesis. Dev. Genet. 1996, 19, 249-257.

3. Phizicky, E.; Bastiaens, P. I. H.; Zhu, H.; Snyder, M.; Fields, S. Protein Analysis on a Proteomic Scale. Nature 2003, 422, 208-215.

4. Raina, A. K.; Sayre, L.; Zhu, X.; Cash, A.; Perry, G.; Smith, M. A. Acetylation: A Novel Posttranslational Modification in Alzheimer Disease. J. Neuropath. Exp. Neur. 2003, 62, 550-551.

5. Wang, J. Z.; GrundkeIqbal, I.; Iqbal, K. Glycosylation of MicrotubuleAssociated Protein Tau: An Abnormal Posttranslational Modification in Alzheimer's Disease. Nat. Med. 1996, 2, 871-875.

6. Guo, L.; Munzberg, H.; Stuart, R. C.; Nillni, E. A.; Bjorbaek, C. $\mathrm{N}$-Acetylation of Hypothalamic $\alpha$-Melanocyte-Stimulating Hormone and Regulation by Leptin. PNAS 2004, 101, 11797-11802.

7. Dierks, T.; Schmidt, B.; Borissenko, L. V.; Peng, J. H.; Preusser, A. Mariappan, M.; von Figura, K. Multiple Sulfatase Deficiency is Caused by Mutations in the Gene Encoding the Human C- $\alpha$-Formylglycine Generating Enzyme. Cell 2003, 113, 435-444.

8. Hoozemans, J. J. M.; Stieler, J.; van Haastert, E. S.; Veerhuis, R.; Rozemuller, A. J. M.; Baas, F.; Eikelenboom, P.; Arendt, T.; Scheper, W. The Unfolded Protein Response Affects Neuronal Cell Cycle Protein Expression: Implications for Alzheimer's Disease Pathogenesis. J. Exp. Ger. 2006, 41, 380-386.

9. Aebersold, R.; Mann, M. Mass Spectrometry-Based Proteomics. Nature 2003, 422, 198-207.
10. Hanash, S. Disease Proteomics. Nature 2003, 422, 226-232.

11. Stoeckli, M.; Chaurand, P.; Hallahan, D. E.; Caprioli, R. M. Imaging Mass Spectrometry: A New Technology for the Analysis of Protein Expression in Mammalian Tissues. Nat. Med. 2001, 7, 493-496.

12. Pierson, J.; Norris, J. L.; Aerni, H. R.; Svenningsson, P.; Caprioli, R. M.; Andren, P. E. Molecular Profiling of Experimental Parkinson's Disease: Direct Analysis of Peptides and Proteins on Brain Tissue Sections by MALDI Mass Spectrometry. J. Proteome Res. 2004, 3, 289-295.

13. Pierson, J.; Svenningsson, P.; Caprioli, R. M.; Andren, P. E. Increased Levels of Ubiquitin in the 6-OHDA-Lesioned Striatum of Rats. I. Proteome Res. 2005, 4, 223-226.

14. Altelaar, A. F. M.; Klinkert, I.; Jalink, K.; deLange, R. P. J.; Adan, R. A. H.; Heeren, R. M. A.; Piersma, S. R. Gold-Enhanced Biomolecular Surface Imaging of Cells and Tissue by SIMS and MALDI Mass Spectrometry. Anal. Chem. 2006, 78, 734-742.

15. Skold, K.; Svensson, M.; Nilsson, A.; Zhang, X. Q.; Nydahl, K.; Caprioli, R. M.; Svenningsson, P.; Andren, P. E. Decreased Striatal Levels of PEP-19 Following MPTP Lesion in the Mouse. J. Proteome Res. 2006, 5, 262-269.

16. Tanaka, K.; Waki, H.; Ido, Y.; Akita, S.; Yoshida, Y.; Yoshida, T.; Matsuo, T. Protein and Polymer Analyses up to $m / z 100,000$ by Laser Ionization Time-of-Flight Mass Spectrometry. Rapid Commun. Mass Spectrom. 1988, 2, 151-153.

17. Karas, M.; Bachmann, D.; Bahr, U.; Hillenkamp, F. Matrix-Assisted Ultraviolet Laser Desorption of Nonvolatile Compounds. Int. J. Mass Spectrom. Ion Processes 1987, 78, 53-68.

18. Van Vaeck, L.; Adriaens, A.; Gijbels, R. Static Secondary Ion Mass Spectrometry: (S-SIMS) Part 1. Methodology and Structural Interpretation. Mass Spectrom. Rev. 1999, 18, 1-47.

19. Vickerman, J. C.; Briggs, D. E. TOF-SIMS: Surface Analysis by Mass Spectrometry; IM Publications: Chichester, UK, 2001, 1-41.

20. Sjovall, P.; Lausmaa, J.; Johansson, B. Mass Spectrometric Imaging of Lipids in Brain Tissue. Anal. Chem. 2004, 76, 4271-4278.

21. Altelaar, A. F. M.; van Minnen, J.; Jimenez, C. R.; Heeren, R. M. A. Piersma, S. R. Direct Molecular Imaging of Lymnaea stagnalis nervous tissue at subcellular spatial resolution by mass spectrometry. Anal. Chem. 2005, 77, 735-741.

22. Adriaensen,, L., Vangaever,, F., Lenaerts,, J., Gijbelsa,, R. S-SIMS and MetA-SIMS Study of Organic Additives in Thin Polymer Coatings. Appl. Surf. Sci, 2006, 252, 6628-6631.

23. Adriaensen, L.; Vangaever, F.; Gijbels, R. Organic SIMS: The Influence of Time on the Ion Yield Enhancement by Silver and Gold Deposition. Appl. Surf. Sci. 2004, 231-2, 256-260.

24. Adriaensen, L.; Vangaever, F.; Gijbels, R. Metal-Assisted Secondary Ion Mass Spectrometry: Influence of Ag and Au Deposition on Molecular Ion Yields. Anal. Chem. 2004, 76, 6777-6785.

25. Delcorte, A.; Bour, J.; Aubriet, F.; Muller, J. F.; Bertrand, P. Sample Metallization for Performance Improvement in Desorption/Ionization of Kilodalton Molecules: Quantitative Evaluation, Imaging Secondary Ion MS, and Laser Ablation. Anal. Chem. 2003, 75, 6875-6885.

26. Luxembourg, S. L.; McDonnell, L. A.; Duursma, M. C.; Guo, X. H.; Heeren, R. M. A. Effect of Local Matrix Crystal Variations in MatrixAssisted Ionization Techniques for Mass Spectrometry. Anal. Chem. 2003, 75, 2333-2341.

27. McDonnell, L. A.; Mize, T. H.; Luxembourg, S. L.; Koster, S.; Eijkel, G. B.; Verpoorte, E.; de Rooij, N. F.; Heeren, R. M. A. Using Matrix Peaks to Map Topography: Increased Mass Resolution and Enhanced Sensitivity in Chemical Imaging. Anal. Chem. 2003, 75, 4373-4381.

28. McDonnell, L. A.; Piersma, S. R.; Altelaar, A. F. M.; Mize, T. H.; Luxembourg, S. L.; Verhaert, P. D. E. M.; van Minnen, J.; Heeren, R. M. A. Subcellular Imaging Mass Spectrometry of Brain Tissue. J. Mass Spectrom. 2005, 40, 160-168.

29. McDonnell, L. A.; Heeren, R. M. A.; de Lange, R. P. J.; Fletcher, I. W. Higher Sensitivity Secondary Ion Mass Spectrometry of Biological Molecules for High Resolution, Chemically Specific Imaging. J. Am. Soc Mass Spectrom. 2006, 17, 1195-1202. 
30. Nygren, H.; Malmberg, P.; Kriegeskotte, C.; Arlinghaus, H. F. Bioimaging TOF-SIMS: Localization of Cholesterol in Rat Kidney Sections. Febs. Lett. 2004, 566, 291-293.

31. Chaurand, P.; Schwartz, S. A.; Caprioli, R. M. Profiling and Imaging Proteins in Tissue Sections by MS. Anal. Chem. 2004, 76, 86A-93A.

32. Kruse, R.; Sweedler, J. V. Spatial Profiling Invertebrate Ganglia Using MALDI MS. J. Am. Soc. Mass Spectrom. 2003, 14, 752-759.

33. Spengler, B.; Hubert, M. Scanning Microprobe Matrix-Assisted Laser Desorption Ionization (SMALDI) Mass Spectrometry: Instrumentation for Submicrometer Resolved LDI and MALDI Surface Analysis. J. Am. Soc. Mass Spectrom. 2002, 13, 735-748.

34. Luxembourg, S. L.; Mize, T. H.; McDonnell, L. A.; Heeren, R. M. A High-Spatial Resolution Mass Spectrometric Imaging of Peptide and Protein Distributions on a Surface. Anal. Chem. 2004, 76, 5339-5344

35. McLafferty, F. W.; Kelleher, N. L.; Begley, T. P.; Fridriksson, E. K.; Zubarev, R. A.; Horn, D. M. Two-Dimensional Mass Spectrometry of Biomolecules at the Subfemtomole Level. Curr. Opin. Chem. Biol. 1998, 2, 571-578.

36. Marshall, A. G.; Hendrickson, C. L.; Jackson, G. S. Fourier Transform Ion Cyclotron Resonance Mass Spectrometry: A primer. Mass Spectrom. Rev. 1998, 17, 1-35.

37. Castoro, J. A.; Wilkins, C. L. High-Resolution Laser-Desorption Ionization Fourier-Transform Mass-Spectrometry. TrAC-Trends Anal. Chem. 1994, 13, 229-233.

38. Li, Y. Z.; McIver, R. T.; Hunter, R. L. High-Accuracy Molecular-Mass Determination for Peptides and Proteins by Fourier-Transform Mass Spectrometry. Anal. Chem. 1994, 66, 2077-2083.

39. Kutz, K. K.; Schmidt, J. J.; Li, L. J. In Situ Tissue Analysis of Neuropeptides by MALDI FTMS In-Cell Accumulation. Anal. Chem. 2004, 76, 5630-5640.

40. Paxinos, G.; Watson, C. Rat Brain Steretaxic Coordinates; 4th ed.; Academic Press: San Diego, 1998, p 26.

41. Schwartz, S. A.; Reyzer, M. L.; Caprioli, R. M. Direct Tissue Analysis Using Matrix-Assisted Laser Desorption/Ionization Mass Spectrometry: Practical Aspects of Sample Preparation. J. Mass Spectrom. 2003, 38 , 699-708.

42. Hanton, S. D.; Clark, P. A. C.; Owens, K. G. Investigations of MatrixAssisted Laser Desorption/Ionization Sample Preparation by Time-of-
Flight Secondary Ion Mass Spectrometry. J. Am. Soc. Mass Spectrom. $1999,10,104-111$.

43. Hensel, R. R.; King, R. C.; Owens, K. G. Electrospray Sample Preparation for Improved Quantitation in Matrix-Assisted Laser Desorption/ Ionization Time-of-Flight Mass Spectrometry. Rapid Commun. Mass Spectrom. 1997, 11, 1785-1793.

44. Baykut, G.; Jertz, R.; Witt, M. Matrix-Assisted Laser Desorption/ Ionization Fourier Transform Ion Cyclotron Resonance Mass Spectrometry with Pulsed In-Source Collision Gas and In-Source Ion Accumulation. Rapid Commun. Mass Spectrom. 2000, 14, 1238-1247.

45. Schueler, B.; Sander, P.; Reed, D. A. A Time-of-Flight Secondary Ion-Microscope. Vacuum 1990, 41, 1661-1664.

46. Schueler, B. W. Microscope Imaging by Time-of-Flight Secondary Ion Mass-Spectrometry. Microsc. Microanal. Microstruct. 1992, 3, 119-139.

47. Mize, T. H.; Taban, I.; Duursma, M.; Seynen, M.; Konijnenburg, M. Vijftigschild, A.; Doornik, C. V.; Rooij, G. V.; Heeren, R. M. A. A Modular Data and Control System to Improve Sensitivity, Selectivity, Speed of Analysis, Ease of Use, and Transient Duration in an External Source FTICR-MS. Int. J. Mass Spectrom. 2004, 235, 243-253.

48. Klinkert,, I., Luxembourg," S. L., Altelaar,, A. F. M., Amstalden,, E., Piersma, S. R., Konijnenburg, M., McDonnell, L. A., Heeren, R. M. A A New Problem Solving Environment for Data Intensive High-Spatial Resolution Imaging Mass Spectrometry Experiments. Rev. Sci. Instr., in press.

49. Smith, R. D. Evolution of ESI-Mass Spectrometry and Fourier Transform Ion Cyclotron Resonance for Proteomics and Other Biological Applications. Int. J. Mass Spectrom. 2000, 200, 509-544.

50. Hernando, F.; Schoots, O.; Lolait, S. J.; Burbach, J. P. H. Immunohistochemical Localization of the Vasopressin V1b Receptor in the Rat Brain and Pituitary Gland: Anatomical Support for Its Involvement in the Central Effects of Vasopressin. Endocrinology 2001, 142, 1659-1668.

51. Ludwig, M. Dendritic Release of Vasopressin and Oxytocin. J. Neuroendocrinol. 1998, 10, 881-895.

52. Wotjak, C. T.; Kubota, M.; Liebsch, G.; Montkowski, A.; Holsboer, F.; Neumann, I.; Landgraf, R. Release of Vasopressin Within the Rat Paraventricular Nucleus in Response to Emotional Stress: A Nove Mechanism of Regulating Adrenocorticotropic Hormone Secretion? J. Neurosci. 1996, 16, 7725-7732. 